\section{A REVOLUTION IN DISASTER VICTIM IDENTIFICATION}

Scientists at Queen Mary, University of London have developed an online interactive tool which will enable experts to assess people's teeth and accurately estimate their age. With this tool, forensic teams across the world will be better equipped to identify the age of people who die in natural disasters.

The London Tooth Atlas is a culmination of years of research from Dr Helen Liversidge and her team at Queen Mary dedicated to dental development. The Atlas was underpinned by the need to estimate the ages of victims of the 2004 Indian Ocean tsunami using dental data.

The hard copy version of the London Tooth Atlas was used in a number of disasters such as the New Zealand earthquake in 2011.

'We expect the new software will revolutionise the way forensics determine the age of victims,' said Dr Liversidge.

The tool also enables experts and students to see how teeth change between the ages of 30 weeks in utero to about 23 years.

Dr Sakher AlQahtani, who works with Dr Liversidge, developed the London Tooth Atlas for his postgraduate research project.

The software is available at www.atlas.dentistry.qmul.ac.uk and a related app will follow.

\section{TANZANIANS TAKE PART IN NATIONAL SMILE MONTH}

Volunteers from Bridge2Aid (B2A), the dental and development charity, spread the messages of the National Smile Month campaign run by the British Dental Health Foundation among the people of Tanzania.

The theme of this year's National Smile Month (20 May20 June) was based around the 'Smiley on a stick', which had the three key messages of the campaign printed on the back. B2A introduced the campaign to its patients in Tanzania to help educate them about the importance of oral health.

'We want people in both the UK and East Africa to understand that they can take simple steps to protect their oral health,' said Mark Topley, Chief Executive of B2A.

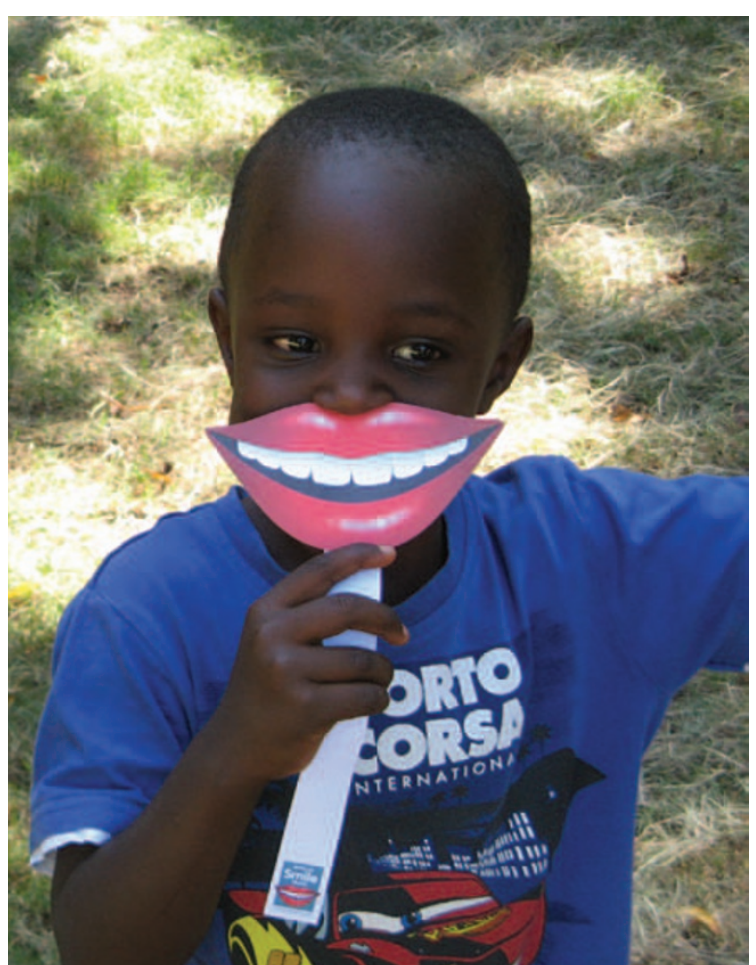

\title{
LEEDS EXPANDS DISTANCE LEARNING OFFERINGS
}

Holders of the FGDP (UK)

Diploma in Implant Dentistry now have one more flexible option for their professional and personal development. The Master of Science (MSc) in Clinical Dentistry (Implant Dentistry) is a new 12-month distance learning programme being offered by Leeds Dental Institute from September 2012.

The course is formally articulated with the Faculty of General Dental Practice (UK) and is a flexible way to convert the FGDP diploma to an MSc in Clinical Dentistry. The course will focus on the development and completion of original research. It aims to build on the candidates' knowledge and experience to extend their academic reach and further develop their research skills. The course combines taught modules in Research Methodology and Ethics \& Statistics, and final assessment is by a presented MSc thesis, usually a research project undertaken within dental practice. Candidates are only required to be on campus for seven days for core study sessions and assessments.

Leeds Dental Institute also offers a similar distance learning course, the MSc in Clinical Dentistry (Restorative Dentistry) for holders of the FGDP (UK) Diploma in Restorative Dentistry.

For more information or to apply, telephone Jo Ward on 0113343 6199, email dentistry@leeds.ac.uk or visit www.leeds.ac.uk/dental.

\section{BDA BULLETIN}

- Long-standing BDA member Helen Chapman, Research Fellow at Lincoln University, is undertaking a project with funding from the Shirley Glasstone Hughes Trust, looking into dentists' decisionmaking. Her project will ask if dentists' fear has an adverse reaction on clinical decisionmaking and is seeking volunteers to participate in the study. The research is being carried out within a 50 mile radius of Lincoln. If you would like to take part, please email hchapman@lincoln.ac.uk.

BDA local groups are looking for volunteers, in particular interested parties who live in Bolton, central
Birmingham, Kesteven and Holland (Stamford area) Plymouth, Sefton and North Liverpool, and Warwickshire and Coventry. BDA local groups rely on volunteers to help run them, organise meetings, seek out venues, speakers and valuable topics to provide free or affordable CPD to all dentists in a local, social and friendly environment. Support and training is offered by the BDA centrally, with annual training each autumn. If you are interested please contact Sue Jones at s.jones@bda.org. 